\title{
7
}

\section{Initial tests on the three-dimensional movement of starch in sediments}

Michael Haslam

\author{
Postdoctoral Fellow in Palaeolithic Archaeology \\ Leverhulme Centre for Human Evolutionary Studies \\ University of Cambridge \\ Cambridge CB2 10H \\ United Kingdom \\ mah66@cam.ac.uk
}

\begin{abstract}
Archaeological studies of microbotanical remains must consider taphonomic factors likely to have affected a recovered assemblage. One of the most fundamental taphonomic considerations is the movement of objects within a soil profile under the influence of groundwater. To this end, this study reports on initial tests involving the movement of starch granules in three dimensions within a constructed sand matrix. The results indicate that both lateral and upward as well as significant downward movement occurs under the influence of groundwater, with movement rates of up to $4 \mathrm{~mm} /$ day for some starch granules greater than $10 \mu \mathrm{m}$ in size.
\end{abstract}

Keywords: starch, taphonomy, post-depositional movement, sediment, microscopy

\section{Introduction}

Analyses of starch granules from archaeological soils complement other, longer-established microbotanical techniques including pollen and phytolith studies. As in these other fields, starch analysts are increasingly recognising the influence of taphonomic factors on constructing and biasing the recovered microfloral suite (Babot 2003; Barton et al. 1998; Haslam 2004). Of critical taphonomic importance is the estimation of starch movement through a soil profile following deposition. Pioneering work in this regard was undertaken in the early 1990s by Fullagar, Loy and Cox (Fullagar et al. 1994), and later developed and elaborated on by Therin (1998, see also 1994) in the first publication on the topic directed towards archaeologists. To date Therin's study remains the sole published starch movement study, with subsequent ancient starch studies often citing his finding that very little starch appears to move in soils (e.g. Fullagar et al. 1998:56; Lentfer et al. 2002:687; Therin et al. 1999:450), or omitting discussion of starch movement altogether (e.g. Barton 2005; Parr and Carter 2003). Therin's findings were 
based on downward percolation of starch of varying sizes through sterile sands, under the influence of significant levels of water simulating heavy rainfalls. His main conclusions were that small starch granules will move more often and faster than large granules, and that larger granules will move more slowly but further than smaller granules once mobile. Therin also suggested that future studies should investigate lateral and upward movement of starch, in addition to other tests. Following this advice, here I report the results of a recent experiment into the three-dimensional (3D) movement of starch in sediments.

\section{Methods}

One of the goals of the current experiment was to produce results which complement previous starch movement studies, and the methods for assessing starch movement were therefore deliberately chosen to build on and augment Therin's $(1994,1998)$ experiments. Certain parameters (including the amount of starch added to the experiment, and the rainfall rate simulation) were mirrored as precisely as practicable, while other parameters (including extraction procedures and the makeup of the sedimentary matrix) differed out of necessity.

\section{The experiment}

The 3D experimental design required a starch sample to be placed in the centre of a constructed sediment matrix with the freedom to move up, down and sideways under the influence of water. To this end, an apparatus was constructed of four $10 \mathrm{~cm}$ sections of $10 \mathrm{~cm}$ diameter PVC piping, cut in half lengthwise and joined to create an open cruciform structure (see Figure 1). Three of the four 'arms' of the cross were blocked with semi-circular wooden stops, which had several holes drilled in them to permit water flow. A piece of synthetic scouring pad was placed against the inner surface of each of the wooden stops to prevent loss of sediment. Four mm thick transparent perspex was cut to match the cruciform shape, and each of the exposed walls of the PVC pipes was lined with a thin foam/rubber window seal strip, with the result that the perspex could be pressed against the open apparatus to create a waterproof seal, and then removed again with ease. The transparent perspex enabled continuous monitoring of the sediment matrix for the development of cracks or other events that may have influenced starch movement. A metal bracket was attached to the back of the cross arm which did not have a wooden stop; this arm formed the 'top' of the apparatus during the experiment.

Sand was chosen as the sediment matrix for the experiment, following Therin (1998). 'Medium' sand was obtained from a commercial supplier, and dry-sieved through a series of Endecott test sieves of mesh sizes varying from $125 \mu \mathrm{m}$ to $1 \mathrm{~mm}$. The $250-$ $500 \mu \mathrm{m}$ fraction was selected for the experiment as this could be expected to leave a matrix

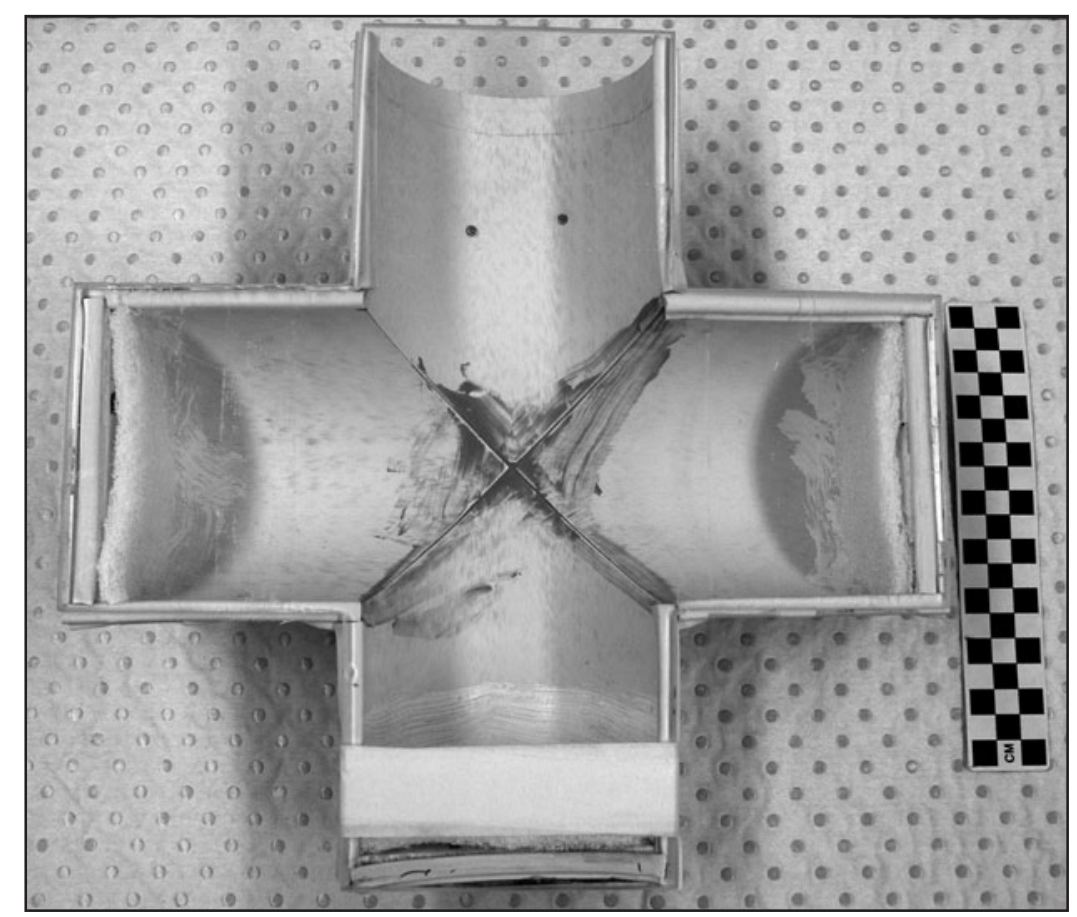

Figure 1. 30 starch movement apparatus with perspex cover. 
permeable and porous enough to permit starch movement. As the sand was dry-sieved, some grains $<250$ $\mu \mathrm{m}$ remained in the $250-500 \mu \mathrm{m}$ fraction through aggregation. It was not desirable to construct a matrix that excluded the possibility of starch movement (for example a dense clay), or one that allowed free movement to all granules (for example loose-packed coarse sand), since this would be self-defeating. As the present study was an initial test of 3D starch movement, it was decided to err on the side of allowing movement rather than restricting it, while still constructing a plausible matrix. The sand was autoclaved for $30 \mathrm{mins}$ at $121^{\circ} \mathrm{C}$ and $105 \mathrm{kPa}$ prior to use in the experiment to eliminate starch-degrading fungi and bacteria, and a sample run through the starch extraction procedure described in the following section to check for contaminants.

With the cruciform apparatus upright (that is, with the wooden stops at the base and side arms of the cross, and the top arm open) and the perspex firmly attached with masking tape, dry packed sand was added to half-fill the apparatus. Using a funnel and a cut-down section of a plastic pipette, $0.1 \mathrm{~g}$ of commercial corn starch was added to the centre of the sand (Figure 2). The corn starch chosen has starch granules which range in size from $2-27 \mu \mathrm{m}$ (average 9.07 $\mu \mathrm{m})$, based on measurements taken from more than 2000 granules. Dry packed sand was then added to fill the apparatus to a level $1 \mathrm{~cm}$ below the top. The whole experiment was hung from a retort stand via the metal bracket attached to the back (Figure 3), allowing it to hang freely vertical. $500 \mathrm{ml}$ of ultrapure water was gradually added to the experiment over the period of a day to initially dampen the sand.

The choice of water volume to be added to the experiment was again based on Therin $(1994,1998)$ to allow comparability. The irrigation of three of Therin's four starch movement columns corresponded to $4777 \mathrm{~mm}$ of rainfall over two months (Therin 1994:53; incorrectly recorded as $4777 \mathrm{ml}$ in Therin 1998:63). The present experiment ran over a period of one month (30 days) and aimed therefore to simulate approximately $2400 \mathrm{~mm}$ rainfall. With a cross-

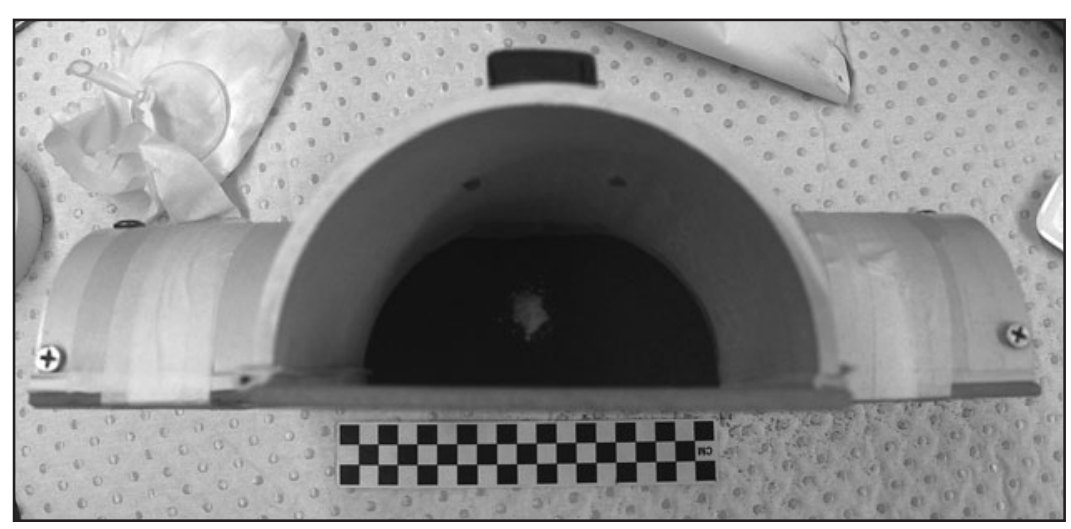

Figure 2. Starch added to experiment.

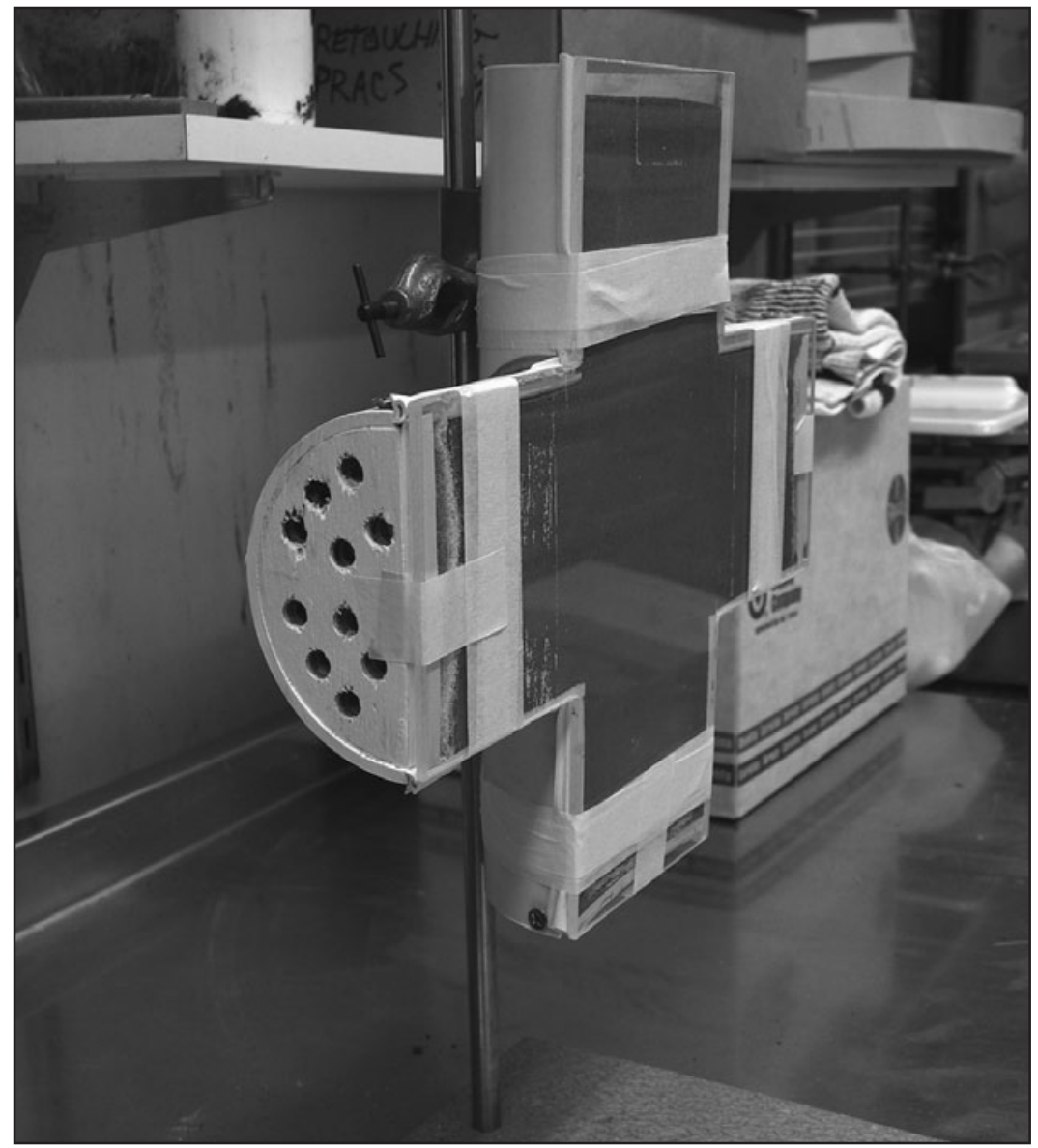

Figure 3. Experiment attached to retort stand. Note holes in wooden stop at end of arm to permit water flow. 
section of $40 \mathrm{~cm} 2$ for the current experiment $2400 \mathrm{~mm}$ corresponds to a total irrigation of $9600 \mathrm{ml}$ over 30 days, or $320 \mathrm{ml} /$ day. This irrigation rate was achieved by adding $160 \mathrm{ml}$ of ultrapure water twice a day, in the morning and evening. As one of Therin's conclusions was that a high irrigation rate probably washed a large number of starch granules entirely out of his experimental column (Therin 1998:71), all water passing through the 3D experiment was collected in a separate petrie dish each day. Daily $20 \mu$ l slides were made fr om the basal waste water, and additional slides were made at regular intervals of the water passing through the side arms, although the volume of water in these cases was less than that passing downwards through the basal arm. When not being irrigated, the top of the apparatus was covered with cling film to prevent evaporation, and the whole experiment kept in a cool area away from direct sunlight.

\section{Sampling}

Following the end of irrigation, the experiment was laid flat and the perspex removed. Sediment samples were taken at $2 \mathrm{~cm}$ intervals along each arm of the cross, starting from the initial central starch addition point, using a section of plastic pipette tube with a $6 \mathrm{~mm}$ inner diameter to 'core' into the sand matrix. The tube was cleaned thoroughly with ethanol between samples, and clean non-starched gloves were worn at all times. Twenty-five samples were collected from along the main cruciform axes, and an additional four samples were collected at diagonals to the axes for a total of 29 samples (Figure 4). Collected samples were transferred to $10 \mathrm{ml}$ conical-base plastic tubes with screw-top caps.

\section{Starch extraction}

Starch extraction involved first deflocculation then heavy liquid separation steps, based in part on Horrocks (2005). The procedure is summarised in Table 1 . The use of sterile

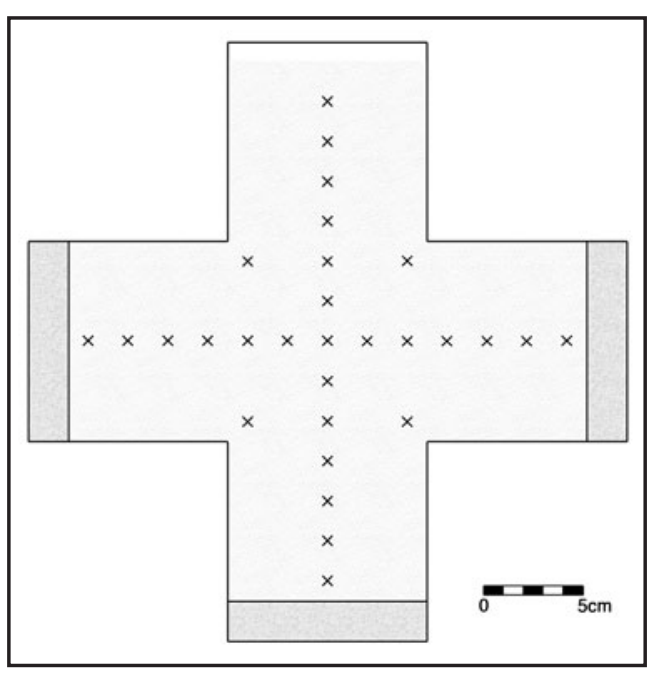

Figure 4. Sediment sample points. sand as a matrix obviated the use of more time-consuming extraction protocols designed to remove organics and other unwanted soil components. Important differences between this protocol and that employed by Therin (1994) include the use of non-toxic sodium polytungstate as opposed to caesium chloride for density separation, and lower centrifuge speeds owing to the equipment available at the University of Queensland Department of Earth Sciences sample preparation laboratory.

1. Place $2 \mathrm{~g}$ sediment in a $10 \mathrm{ml}$ conical-base plastic sample tube.

2. Add $6 \mathrm{ml} 5 \%$ sodium hexametaphosphate solution to each $10 \mathrm{ml}$ tube for deflocculation. Leave samples overnight, shake vigorously occasionally to assist sediment breakup.

3. Pour sample into $50 \mathrm{ml}$ beaker, swirl and decant back into $10 \mathrm{ml}$ tube. Add $3 \mathrm{ml}$ water to beaker and repeat. Make tube volume up to $10 \mathrm{ml}$ using water. Dispose of settled fraction in beaker.

4. Centrifuge $10 \mathrm{ml}$ tube at $3000 \mathrm{rpm}$ for $3 \mathrm{~min}$, decant and dispose of supernatant.

5. Add water to $10 \mathrm{ml}$ in tube, vortex to disaggregate pellet, centrifuge at 3000rpm for $3 \mathrm{~min}$, then decant. Repeat until supernatant is clear.

6. Add $3 \mathrm{ml}$ sodium polytungstate solution (1.7 specific gravity), vortex briefly, then centrifuge at 1500rpm for $3 \mathrm{~min}$. Pipette separated top layer into a second tube, add another $1 \mathrm{ml}$ sodium polytungstate to the first tube, and repeat centrifugation and removal of separated layer.

7. Add water to $10 \mathrm{ml}$ in second tube. Vortex, then centrifuge at 3000rpm for $6 \mathrm{~min}$ and decant supernatant (NB: keep the supernatant from steps 6 and 7 for sodium polytungstate recovery).

8. Add water to $10 \mathrm{ml}$, vortex briefly, centrifuge at $3000 \mathrm{rpm}$ for $3 \mathrm{~min}$. Discard supernatant, leaving ca. $100 \mu \mathrm{l}$ water with starch pellet in tube.

9. Stir sample, transfer $20 \mu \mathrm{l}$ to microscope slide.

Table 1. Summary of starch extraction procedure. 


\section{Analysis}

Analysis was conducted using an Olympus BX50 light microscope fitted with polarising filters, rotating stage and 100-1000x magnification. All slides made from the waste water collected each day and the starch extractions were initially scanned at 100x in cross-polarised light. Examination of possible starch granules and size/shape recording were carried out at 400x. Every starch granule on each slide was recorded using a transect approach to ensure complete slide coverage.

\section{Results}

\section{Porosity calculations}

That the sand matrix permitted the flow of water attests to its permeability, although this attribute was not further quantified. For porosity calculations, an approximation can be obtained by taking the lower limit of sieved particle size (excluding minor attached smaller particles) of $250 \mu \mathrm{m}$, and using the equations:

1. Porosity $=100 \times(1-[$ bulk density/particle density $])$

2. Average pore space $=[$ porosity $(\%) /$ soil particle volume $(\%)] \times$ average particle diameter.

Bulk density in (1) is a measure of the weight of the sediment per unit volume (i.e. $\mathrm{g} / \mathrm{cm} 3)$. In the present experiment, the bulk density may be calculated from the dry weight of the sand added to the apparatus $(2957 \mathrm{~g}$ ) and the volume taken up by that sand (calculated at $1688 \mathrm{~cm} 3)$, leaving a bulk density of $1.7518 \mathrm{~g} / \mathrm{cm} 3$. Particle density in this instance can be taken as 2.65 , the specific gravity of quartz. Using equation (1), this produces a porosity of just under $34 \%$, which is typical for packed sand with little grain-size variation (Tolman 1937:115). The average pore space for $250 \mu \mathrm{m}$ sand can then be calculated as $128.16 \mu \mathrm{m}$ using equation (2), given that the percentages of porosity and soil particle volume must add to $100 \%$. Clearly this allows for movement of particles above the size range of the corn starch in the experiment, although the presence of some particles below $250 \mu \mathrm{m}$ which were not removed during sieving would reduce the available pore space and permeability of the matrix somewhat.

\section{Starch waste water slides}

A total of 38 slides were collected from the waste water passing through the experiment. None of these contained starch granules, of any size. The waste water did contain sedimentary particles up to approximately $5 \mu \mathrm{m}$ diameter, however, indicating that any starch granules of this size or smaller which had migrated through the sand matrix would have been able to exit the experiment. The complete lack of starch suggests that either small starch granules were not able to move beyond $13 \mathrm{~cm}$ (the distance from the starch addition point to the water exit point) under the sedimentary and watering parameters of this experiment, or they did so in undetectably low numbers.

\section{Sediment extractions}

Of the 29 samples removed from the experiment, 27 were run through the extraction procedure outlined in Table 1, along with the control autoclaved sand sample. The two samples not analysed were those closest to the point of water addition at the top of the apparatus. Starch was recovered from nine of the 27 samples, while no starch was recovered from the control sample. Figure 5 shows the frequency of starch granules recovered from these nine locations. The highest number of starch granules $(n=237)$ was, as expected, recovered from the sediment sample at the starch addition point at the centre of the experiment. The next highest frequency $(\mathrm{n}=44)$ was $2 \mathrm{~cm}$ below the starch addition point, and the third highest frequency $(\mathrm{n}=6) 2 \mathrm{~cm}$ to one side of the addition point, although the latter number is obviously quite low. Only very low numbers of starch granules were recovered from any other location, although three granules were located at a lateral distance of $12 \mathrm{~cm}$, indicating the potential for this kind of movement under the influence of groundwater. One starch granule was recovered from the sediment $2 \mathrm{~cm}$ above the starch addition point. 
The average size of the starch granules recovered from the starch addition point is 13.34 $\mu \mathrm{m}$, while those $2 \mathrm{~cm}$ below is $11.82 \mu \mathrm{m}$. All starch granules recovered from the other seven locations were $>10 \mu \mathrm{m}$ in maximum dimension, and the three starch granules displaced laterally by $12 \mathrm{~cm}$ ranged from 11-26 $\mu \mathrm{m}$. No starch granules below $6 \mu \mathrm{m}$ in size were recovere d from any of the extractions, including the sample at the starch addition point, indicating that these granules were lost during the extraction process. While this is regrettable, archaeological starch analyses frequently focus on starches over $5 \mu \mathrm{m}$ as the storage starches important in human diets are often (though not always) greater than this size (e.g. Torrence et al. 2004). The results

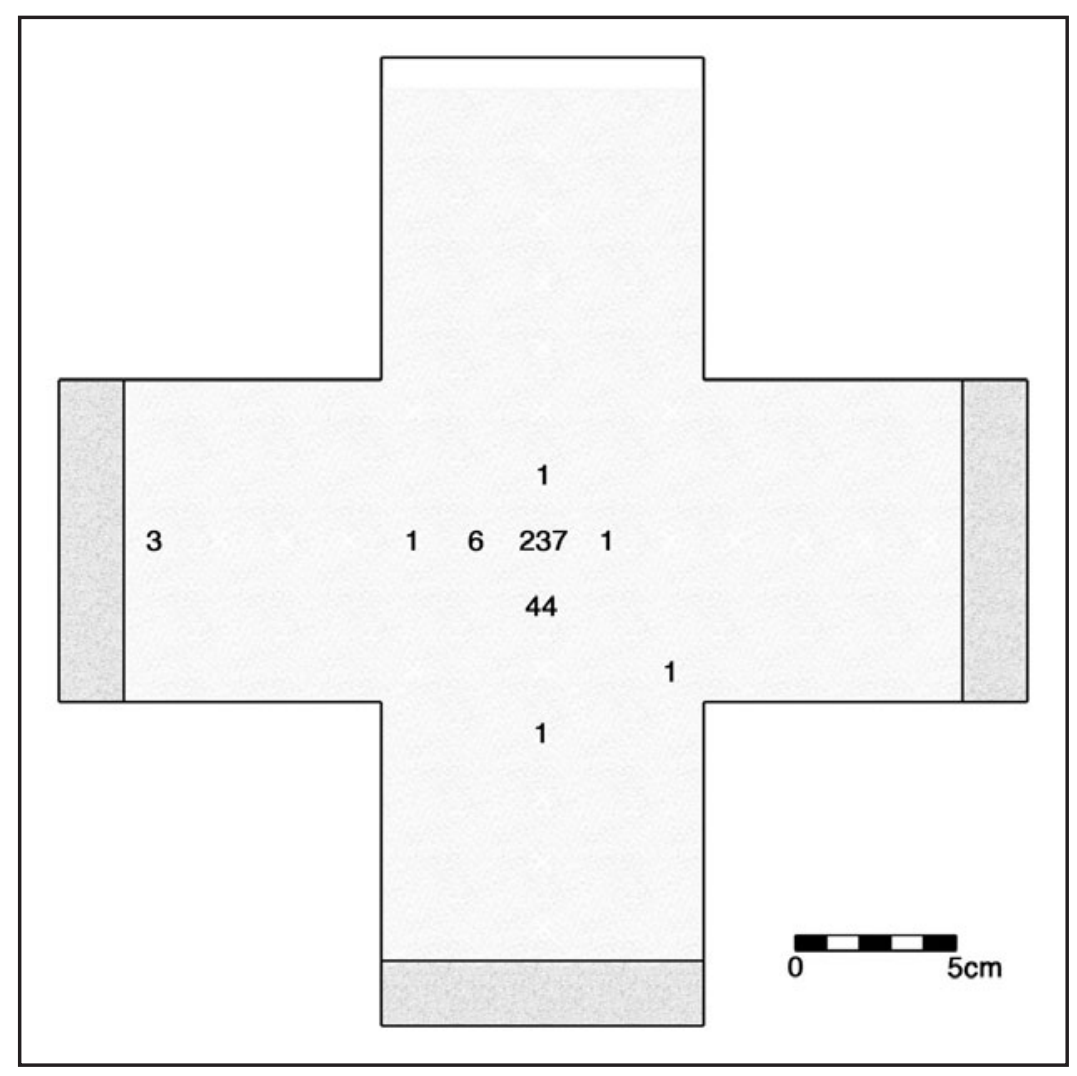
of this initial 3D test therefore carry useful information for ancient starch research, and for assessment of the movement of small starch granules the reader is directed to Therin (1998). The loss of small granules during the extraction process does not affect the monitoring of the experiment waste water, as this was applied directly to each slide without further processing.

\section{Discussion}

Two constructive conclusions can be drawn from this experiment. First, the findings of this study are in concordance with those of Therin $(1994,1998)$ in that only a limited percentage of starch moved any distance within the sediment matrix. Second, the study has shown that lateral and upward movement of starch granules does occur under the influence of groundwater, albeit to a lesser extent than for granules moving with the direction of main water flow.

To draw out these conclusions, Therin's (1998:66) study found that in his experimental column with sand particle sizes and rainfall simulation closest to those of the current study (designated column 1 by Therin), approximately $0.03 \%$ of starch moved downward when compared to starch frequency at the addition point. The percentage in the current experiment is much higher, at almost $16 \%$. To some extent, the difference may be due to the lack of starch granules below $6 \mu \mathrm{m}$ in size counted in the current study, although Therin's starch size breakdown for section B of column 1 (Therin 1998:Figure 5), which is $2 \mathrm{~cm}$ below his starch addition point and therefore comparable to the second highest starch frequency in the 3D study, shows that over $90 \%$ of the starch granules in this section were $>5 \mu \mathrm{m}$. The difference therefore more likely results from the greater porosity afforded by the larger minimum sediment granule size in the current study, and emphasises the necessity of assessing sediment compaction and particle size when interpreting the stability or movement (i.e. provenance) of starches in archaeological sediments. Similarly, it is worth repeating Therin's (1998:71) recognition that finer sediments such as clays and silts will restrict percolating starch movement (while remaining susceptible to cracking and other turbation, as noted below). 
Even though no starch $<6 \mu \mathrm{m}$ was recovered following the 3D experiment extraction procedure, no starch of any size was recovered from the waste water exiting the base or arms of the experiment, showing that very few, and possibly no, small starch granules travelled the necessary $13 \mathrm{~cm}$. While the $3 \mathrm{D}$ experiment was set up to permit starch movement if possible (although not excessively), the results do show that higher numbers of larger starch granules may move than suggested by Therin's initial tests. The movement of even three granules greater than $10 \mu \mathrm{m}$ in size over a distance of $12 \mathrm{~cm}$ in 30 days (a rate of $4 \mathrm{~mm} /$ day) is certainly intriguing, and shows that while mobility may be low in relative terms, it is very real and a factor to consider in interpreting low-frequency archaeological starch data.

It is important to stress that this experiment ran for only 30 days, and the results represent only the beginning of starch movement activity for this sample. There is no reason at this stage to suspect that starch granules will remain stationary following initial movement under the influence of water, and with low recovery rates typical for ancient starch from sediments or artefacts (e.g. Parr and Carter 2003; Perry 2004; see also Haslam 2006 Appendix 2), the possibility that the original starch source was in fact ten or more centimetres away can become significant, particularly in sites where a vertical distance of that magnitude equates to a period of hundreds or thousands of years. It might be tempting to say that the current results imply that most archaeological starch recovered from sediments was collected in its primary context, however consideration of both these and Therin's (1998) results show that this is often likely to be an unwarranted assumption which blurs the record of activity at a site. While artefact residue studies may rely on use-wear corroboration to determine if starches are associated with use (and calculations of artefact movement must of course then still be made), studies of starches directly extracted from archaeological sediments may have to turn more often to starch assemblage composition studies if claims that recovered starch was in its primary context are to be supported (see also palynological discussion below). Other taphonomic issues will however come into play at that point, including differential decay of starches from different species and of different sizes (Haslam 2004).

The second main conclusion and perhaps the most important contribution of this study is that lateral and upward movement of starch granules does occur, although it is clear that this is less significant than downward movement (or more strictly, movement with the main direction of water flow). The implications of this finding for ancient starch research centre mainly on the study of activity areas, although upward movement raises the same issues of incorrect dating or strata association as the downwards movement discussed previously. Two published spatial analyses use starch to identify ancient activity areas, conducted at Petzkes Cave in Australia (Balme and Beck 2002) and at Tor Faraj in Jordan (Rosen 2003; see also Henry et al. 2004). The Australian study identified clear areas of starch concentration in the top $3 \mathrm{~cm}$ of sediment at Petzkes Cave, with all dated hearths from the same layer dating to the last few hundred years (Balme and Beck 2002:163). The authors did consider moisture at the site (based on wet/dry observations following rain), but this did not correlate with the starch pattern. The relatively young age of the site may have played a part in maintaining distinct starch-rich zones, although the portions of the site with the highest starch loadings do possess a halo of decreasing starch content (Balme and Beck 2002: Figure 1) which may have at least partially been influenced by lateral starch movement.

Rosen (2003) sampled a Middle Paleolithic living floor at Tor Faraj, with 0-177 starch granules recovered from each of 30 analysed samples. Four of the samples have $>100$ granules each, while the remainder have $<60$. The three highest recovery sites are recognised as 'concentrations' and translated as spatially discrete areas (Henry et al. 2004:24). Again, these starch-rich clusters possess what may be viewed as a lateral halo of decreasing starch content. Henry et al. (2004:21) report that 'the deposit is in primary context with only minor post-depositional disturbance from low energy sheetwash', although the effect of this lateral water movement is not discussed in relation to the recovered starches. Interestingly, the sediment matrix of the Tor Faraj living floor is comprised of aeolian sand (Henry et al. 2004:20), providing a potentially useful parallel to the current study. As these two studies demonstrate, if ancient starch research continues at its current rate it is likely that increasing numbers of spatial/activity area studies will be conducted that will need to consider the presence and rate of lateral starch movement.

Movement is not confined to that initiated by groundwater, of course, and processes such as physical turbation of sediments, cracking clays and human activity will likely play a part in any starch movement. Whether or not the conditions within a rockshelter or cave differ in the effect of starch 
movement when compared with more open site remains to be seen, although the lesser exposure to rainfall in a shelter could be expected to lead to a reduction in water-induced movement. Sediment starch studies from shelter sites would then need to pay close attention to soil micromorphological evidence where this was available (e.g. McConnell and Magee 1993). As an example, a recent study revealed micromorphological evidence of episodic wetting/drying, water movement and bioturbation molds around $4 \mathrm{~mm}$ in size at Niah Cave, Sarawak (Stephens et al. 2005). A report of the starch analysis of sediments from the site (Barton 2005), however, makes no mention of the possible effects of these (or any other) processes on post-depositional starch movement. Development of closer ties between starch researchers and other soil analysts is one means by which explanations of any presumed mobility or immobility of starch within a sediment profile may be strengthened.

As a final point of comparison, the notion of starches moving through archaeological sediments may be considered in light of previous research into pollen grain movement. Pollen movement through sediments under the influence of water (or percolation) is well studied (Dimbleby 1985; Horrocks and D'Costa 2003; Kelso 1993, 1994a, 1994b; Kelso et al. 1995; Kelso et al. 2000), and relevant to the present study thanks to overlap in grain sizes with starch. Dimbleby (1985) produced detailed theoretical models of pollen movement and preservation at archaeological sites, and his conclusions broadly suggest that the lower one looks in a sediment profile, the higher the percentage of older pollen, and the higher the percentage of degraded pollen grains, one should find. Samples taken from higher up in a profile should contain mixtures of washed-down pollen of various ages, trending towards a high percentage and frequency of recently-deposited pollen grains at the surface. In addition, because of the interplay between percolation and degradation (including differential decomposition), the absolute numbers of pollen grains recovered from a given sample will show a more complex pattern than that calculated via percentages (Dimbleby 1985:5). Subsequent empirical research supports Dimbleby's results (e.g. Horrocks and D'Costa 2003; Kelso 1994a, 1994b; Russell 1993), and emphasises the necessity of not just recording the presence of particular taxa within a given sample, but evaluating the entire microfossil assemblage to accurately identify the influence of movement and degradation. Such results have obvious implications for the conduct of sediment-starch analysis. From archaeological data, calculations of the average rate of downward pollen percolation fall within a range of approximately $1 \mathrm{~cm}$ per 1-30 years (Dimbleby 1985; Horn et al. 1998; Horrocks and D'Costa 2003; Kelso 1994a, 1994b; Kelso et al. 1995), with generally faster rates in tropical and non-forested areas.

Significantly, Dimbleby (1985:2) and others suggest that much of the pollen present in sediments may be trapped within soil aggregates and is not free to move with groundwater. A similar situation has been suggested as a mechanism of starch survival, including the possible triggering of aggregate formation by the starch itself (Haslam 2004:1725). In such cases, it is the breakdown of these aggregates, or their wholesale movement, which is necessary to transport microfossils within the profile (Russell 1993). Both scenarios are frequently accomplished through the agency of macro-fauna. Both pollen and phytolith (e.g. Hart 2003) studies have noted the influence of earthworms, ants and termites in translocating either individual microfossils or soil aggregates. Earthworms in particular may homogenise a considerable volume of soil (Armour-Chelu and Andrews 1994; Canti 2003), although pH and vegetation characteristics will influence the number and species of worms present in a given setting. In a multi-analytical approach, Grave and Kealhofer (1999) used phytoliths to demonstrate that even where there is 'strong evidence of insect activity and percolation' in a Thailand site, microfossils may avoid much of the homogenisation because of their small size $(<50 \mu \mathrm{m})$. Such investigations have yet to be replicated ated by starch analysts, however they indicate that the potential complexity of starch movement should not be underestimated for any site. Starch-specific sediment deposition patterns not seen for other microfossils (e.g. in situ underground decay of starchy organs; see Zarillo and Kooyman 2006:485) also require further study to properly adapt pollen and phytolith results to ancient starch research. 


\section{Conclusion}

All available evidence suggests that starch granules do move through sediments under the influence of groundwater, just as pollen grains, phytoliths, and in fact any sedimentary particle with sufficient space and the appropriate influences will do. The initial testing of three-dimensional movement of starch has shown that upward and particularly lateral movement occurs, although to a lesser degree than downward motion. This movement is not confined to starch granules below $5 \mu \mathrm{m}$ in size (those often considered by archaeologists not to be representative of human economic activity), and starch granules well over $10 \mu \mathrm{m}$ have been shown to move at a rate of up to $4 \mathrm{~mm} /$ day laterally. The volume of water adde $\mathrm{d}$ to the experiment over a period of one month suggests two conflicting caveats when interpreting these results - firstly that rainfall rates in many parts of the world will not be contributing as much water to the soil per day as in this experiment (although certain events, for example floods, sheetwash or irrigation certainly would), and second that the much greater time scale of archaeological sediments is expected to permit much greater movement of mobile starch granules than seen in the current experiment. Future studies will need to vary sediments, water input and time periods according to local conditions of interest. Continued research into the taphonomy of starch granules remains an important component of archaeological starch research, and movement studies employing varying environmental conditions and starch types will form an integral component of such research.

\section{Acknowledgements}

This experiment benefited from discussions with Tom Loy, who also helped build the apparatus and donated his garage and toolkit to that end. I thank Sandra Shearer, Peter Colls, the Department of Earth Sciences, University of Queensland, and Alison Crowther for assistance with various aspects of the project, and those present at the session organised by Judith Field at the Australasian Archaeometry Conference in Canberra, December 2005, where a partial version of this paper was presented, for their ideas. I also thank the anonymous reviewer. The Department of Archaeology and Natural History at the Australian National University assisted with funding to attend the conference. Ian Lilley commented on an earlier draft of this paper. 


\section{References}

Armour-Chelu, M. and P. Andrews. 1994. Some effects of bioturbation by earthworms (Oligochaeta) on archaeological sites. Journal of Archaeological Science 21:433-443.

Babot, M. d. P. 2003. Starch grain damage as an indicator of food processing. In D. M. Hart and L. A. Wallis (eds), Phytolith and starch research in the Australian-Pacific-Asian regions: The state of the art, pp 69-81. Canberra: Pandanus Books.

Balme, J. and W. Beck. 2002. Starch and charcoal: Useful measures of activity areas in archaeological rockshelters. Journal of Archaeological Science 29:157-166.

Barton, H. 2005. The case for rainforest foragers: The starch record at Niah Cave, Sarawak. Asian Perspectives 44(1):56-72.

Barton, H., R. Torrence and R. Fullagar. 1998. Clues to stone tool function re-examined: Comparing starch grain frequencies on used and unused obsidian artefacts. Journal of Archaeological Science 25:1231-1238.

Canti, M. G. 2003. Earthworm activity and archaeological stratigraphy: A review of products and processes. Journal of Archaeological Science 30:135-148.

Dimbleby. G. W. 1985. The palynology of archaeological sites. Studies in archaeological science. New York: Academic Press.

Fullagar, R., T. Loy and S. Cox. 1994. Starch grains in archaeological sediments: Implications for vegetation history and residue studies. Paper presented at the 15th Congress of the Indo-Pacific Prehistory Association, Chiang Mai, Thailand.

Fullagar, R., T. Loy and S. Cox. 1998. Starch grains, sediments and stone tool function: Evidence from Bitokara, Papua New Guinea. In R. Fullagar (ed.), A closer look: Recent Australian studies of stone tools, pp 49-60. Sydney: Archaeological Computing Laboratory, University of Sydney.

Grave, P. and L. Kealhofer. 1999. Assessing bioturbation in archaeological sediments using soil morphology and phytolith analysis. Journal of Archaeological Science 26:1239-1248.

Hart, D. M. 2003. The influence of soil fauna on phytolith distribution in an Australian soil. In D. M. Hart and L. A. Wallis (eds), Phytolith and starch research in the Australian-Pacific-Asian regions: The state of the art, pp 83-91. Canberra: Pandanus Books.

Haslam, M. 2004. The decomposition of starch grains in soils: Implications for archaeological residue analyses. Journal of Archaeological Science 31:1715-1734.

Haslam, M. 2006. Archaeological residue and starch analysis: Interpretation and taphonomy. Unpublished $\mathrm{PhD}$ thesis, School of Social Science, The University of Queensland.

Henry, D. O., H. J. Hietala, A. M. Rosen, Y. E. Demidenko, V. I. Usik, and T. L. Armagan. 2004. Human behavioural organization in the Middle Paleolithic: Were Neanderthals different? American Anthropologist 106 (1):17-31.

Horn, S., K. H. Orvis, J. C. Rodgers and L. A. Northrop. 1998. Recent land use and vegetation history from soil pollen analysis: Testing the potential in the lowland humid tropics. Palynology 22:167-180.

Horrocks, M. 2005. A combined procedure for recovering phytoliths and starch residues from soils, sedimentary deposits and similar materials. Journal of Archaeological Science 32:1169-1175.

Horrocks, M. and D. M. D'Costa. 2003. Stratigraphic palynology in porous soils in humid climates: An example from Pouerua, northern New Zealand. Palynology 27:27-37.

Kelso, G. K. 1993. Pollen-record formation processes, interdisciplinary archaeology, and land use by mill workers and managers: The Boott Mills Corporation, Lowell, Massachusetts, 1836-1942. Historical Archaeology 27(1):70-94.

Kelso, G. K. 1994a. Pollen percolation rates in Euroamerican-era cultural deposits in the northeastern United States. Journal of Archaeological Science 21:481-488.

Kelso, G. K. 1994b. Palynology in historical rural-landscape studies: Great Meadows, Pennsylvania. American Antiquity 59(2):359-372. 
Kelso, G. K., S. A. Mrozowski, D. Currie, A. C. Edwards, M. R. Brown III, A. J. Horning, G. J. Brown and J. R. Dandoy. 1995. Differential pollen preservation in a seventeenth-century refuse pit, Jamestown Island, Virginia. Historical Archaeology 29(2):43-54.

Kelso, G. K., D. Ritchie and N. Misso. 2000. Pollen record preservation processes in the Salem Neck Sewage Plant Shell Midden (19-ES-471), Salem, Massachusetts, U.S.A. Journal of Archaeological Science 27:235-240.

Lentfer, C., M. Therin and R. Torrence. 2002. Starch grains and environmental reconstruction: A modern test case from West New Britain, Papua New Guinea. Journal of Archaeological Science 29:687-698.

McConnell, A. and J. W. Magee. 1993. The contribution of microscopic analysis of archaeological sediments to the reconstruction of the human past in Australasia. In B. L. Fankhauser and J. R. Bird (eds), Archaeometry: Current Australasian research, pp 131-140. Canberra: Department of Prehistory, Research School of Pacific Studies, The Australian National University.

Parr, J. F. and M. Carter. 2003. Phytolith and starch analysis of sediment samples from two archaeological sites on Dauar Island, Torres Strait, northeastern Australia. Vegetation History and Archaeobotany 12:131-141.

Perry, L. 2004. Starch analyses reveal the relationship between tool type and function: An example from the Orinoco valley of Venezuela. Journal of Archaeological Science 31:1069-1081.

Rosen, A.M. 2003. Middle Paleolithic plant exploitation: The microbotanical evidence. In D. O. Henry (ed.) Neanderthals in the Levant: Behavioral organization and the beginnings of human modernity, pp 156-171. London: Continuum.

Russell, E. W. B. 1993. Early stages of secondary succession recorded in soil pollen on the North Carolina piedmont. American Midland Naturalist 129(2):384-396.

Stephens, M., J. Rose, D. Gilbertson and M. G. Canti. 2005. Micromorphology of cave sediments in the humid tropics: Niah Cave, Sarawak. Asian Perspectives 44(1):42-55.

Therin, M. 1994. Subsistence through Starch: The examination of subsistence changes on Garua Island, West New Britain, Papua New Guinea, through the extraction and identification of starch in sediments. Unpublished BA (Hons) thesis. Sydney: Department of Prehistoric and Historical Archaeology, University of Sydney.

Therin, M. 1998. The movement of starch grains in sediments. In R. Fullagar (ed.), A closer look: Recent Australian studies of stone tools, pp 61-72. Sydney: Archaeological Computing Laboratory, University of Sydney.

Therin, M., R. Fullagar and R. Torrence. 1999. Starch in sediments: A new approach to the study of subsistence and land use in Papua New Guinea. In C. Gosden and J. Hather (eds), The Prehistory of Food: Appetites for change, pp 438-462. London: Routledge.

Tolman, C. F. 1937. Ground Water. 1st ed. New York: McGraw Hill.

Torrence, R., R. Wright and R. Conway. 2004. Identification of starch granules using image analysis and multivariate techniques. Journal of Archaeological Science 31:519-532.

Zarillo, S. and B. Kooyman. 2006. Evidence for berry and maize processing on the Canadian plains from starch grain analysis. American Antiquity 71(3):473-500. 